\title{
Trimming of a Broken Migrated Biliary Metal Stent with the Nd:YAG Laser
}

\section{Zuber-Jerger F. Kullmann}

Department of Internal Medicine I, University of Regensburg, Regensburg, Germany

\section{Key Words}

Broken migrated biliary metal stent $\cdot$ Nd:YAG laser $\cdot$ Trimming

\begin{abstract}
Biliary metal stents are a permanent solution for bile duct stenosis. Complications can arise when the stent migrates, breaks or is overgrown by tumour. The following case demonstrates how a Nd:YAG laser can be used to solve these problems. A 93-year-old man presented with jaundice and fever. Two years earlier a $6-\mathrm{cm}$ metal stent had been implanted into a postinflammatory stenosis of the common bile duct after recurrent cholangitis and repetitive plastic stenting. Duodenoscopy showed that the stent was broken. It had migrated about $3 \mathrm{~cm}$ into the duodenum, leading to kinking of the stent and breaking of the wires. The stent was also occluded. It was necessary to purge the common bile duct and to introduce a second stent. However, the only way to reach the papilla was through the broken wires. Placing a second stent this way was impossible. Thus we trimmed the stent with a Nd:YAG laser. The piece that had migrated into the duodenum was retrieved. Now the papilla could be reached. The rest of the metal stent was purged with $\mathrm{NaCl} 0.9 \%$. A second metal stent was placed. Since an Nd:YAG laser is part of the equipment of most endoscopy units, it can be used to trim a broken or migrated biliary metal stent.
\end{abstract}

\section{Background}

Stenosis of the common bile duct [1-3], the pancreatic duct [4] or the oesophagus [5, 6] can be resolved by the implantation of a metal stent. Gastrointestinal metal stents have proven to be a long-lasting solution in situations where surgery is impossible or denied. Complications arising from metal stents are migration, breaking and closure by bolus or tumour ingrowth. The most common complication is tumour ingrowth, which arises in nearly every second patient with oesophagus carcinoma and oesophageal metal stent [7]. This complication can sometimes be avoided by the implantation of a covered metal stent 
[8], and if occurring it can usually be solved by tumour debridement with laser and/or placement of a second stent $[7,8]$. In the biliary tree the problem of tumour ingrowth into a metal stent is usually solved by the placement of a second covered stent.

Breaking and migration of metal stents in the oesophagus and common bile duct can lead to serious clinical problems, such as as complete closure of the bile duct leading to cholestasis, or of the duodenum or oesophagus leading to either ileus or complete inability of food intake. Gastrointestinal haemorrhage or ulceration or perforation due to duodenal erosion by the stent can arise [9-11]. The problem of migration and breaking of a stent can sometimes be solved by trimming the stent with laser and taking it out [12, 13]. We present the case of a patient with a broken migrated biliary metal stent leading to cholestasis and incomplete closure of the duodenum that could be solved by trimming the stent with an Nd:YAG laser.

\section{Case Presentation}

A 93-year-old man presented to the emergency room with fever and jaundice. Two years earlier an uncovered Zilver metal stent (length $6 \mathrm{~cm}$, diameter $10 \mathrm{~mm}$ ) had been implanted into a postinflammatory stenosis of the common bile duct because of recurrent cholangitis. Plastic stents had been occluded every second week and had thus not been able to avoid cholangitis.

At presentation the patient complained of chills and abdominal pain. Clinical examination revealed jaundice and painful palpation of the epigastrium. Fever rose up to $39^{\circ} \mathrm{C}$. Laboratory tests showed elevated bilirubin $(2.6 \mathrm{mg} / \mathrm{dl})$ and gamma-GT $(1,340 \mathrm{U} / \mathrm{l})$, neutrophilia $(82.5 \%)$ and an elevated CRP $(66.48 \mathrm{mg} / \mathrm{dl})$. Duodenoscopy revealed that the stent was totally occluded with detritus and had migrated into the duodenum about $3 \mathrm{~cm}$. This migration had led to a kinking of the stent and the wires of the stent were broken at the curve ( $\underline{\text { fig. }}$ ). Thus, the broken biliary metal stent occluded the common bile duct completely and the duodenum partly. The papilla was inaccessible due to the stent. Ulceration of the duodenal wall with gastrointestinal bleeding or perforation had to be expected. Retrieving the stent seemed unavoidable, but we feared complications such as bleeding due to mucosa maceration and perhaps even perforation of the bile duct when forcefully retrieving a metal stent that was securely impacted in the bile duct after two years in place.

We thus tried to trim the stent at the papilla with an Nd:YAG laser with $308 \mathrm{~J}$ and $50 \mathrm{~W}$. We managed to cut the wires exactly at the papilla. The piece of stent cut off by the laser rested in the duodenum after relaxation of the small intestine with butylscopolamine (fig. 2) and was taken out with a snare. The common bile duct was purged through the stent with $\mathrm{NaCl} 0.9 \%$ and a second metal stent (Ultraflex uncovered, length $8 \mathrm{~cm}$, diameter $10 \mathrm{~mm}$ ) was placed (fig. 3). Injection of contrast dye through a standard catheter showed that the biliary tree was free of detritus and stones and that the stream of bile was adequate. The patient was discharged symptom-free. No biliary complications have arisen in the last two years.

\section{Conclusion}

A Nd:YAG laser is part of the equipment of most endoscopy units. It is used predominantly for malignant oesophageal stenosis $[7,8]$. It can also be used to trim broken or migrated metal stents $[12,13]$, avoiding clinical complications such as bleeding and perforation and allowing, like in our case, further stenting of the common bile duct to resolve cholestasis. 


\begin{tabular}{r|l|l|l} 
Case Repports $/ \mathrm{n}$ & $\begin{array}{l}\text { Case Rep Gastroenterol 2009;3:16-20 } \\
\text { D01: 10.1159/000206976 }\end{array}$ & Published online: March 28, 2009 & $\begin{array}{l}\text { 2009 S. Karger AG, Basel } \\
\text { ISSN 1662-0631 } \\
\text { www.karger.com/crg }\end{array}$ \\
\hline
\end{tabular}

Fig. 1. Two years after implantation the metal stent is completely occluded with detritus and has migrated $3 \mathrm{~cm}$ into the duodenum. The migration has led to a kinking of the stent, resulting in breaking of the wires (arrow).

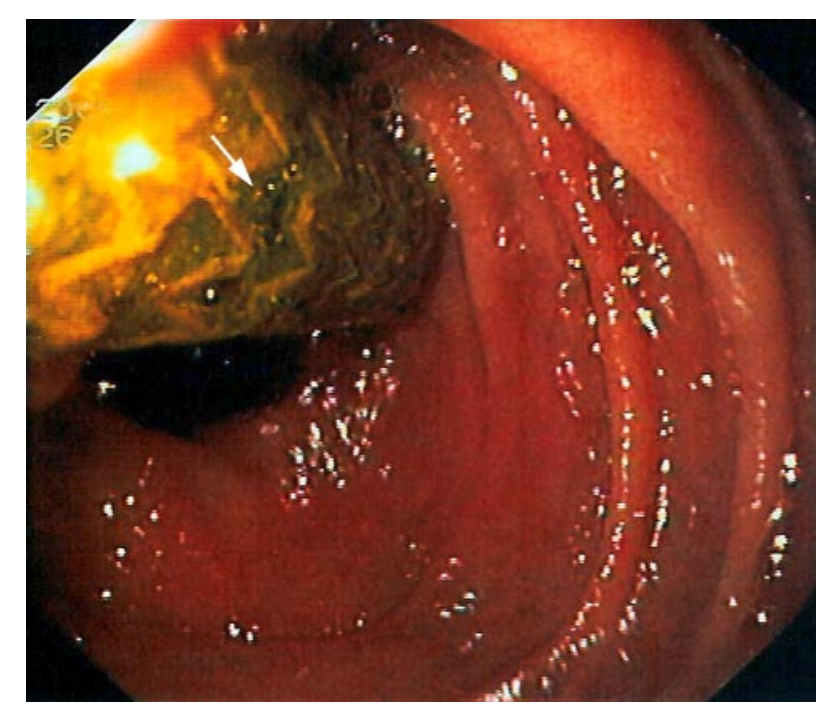

Fig. 2. The part of the metal stent that was cut off rests in the duodenum.

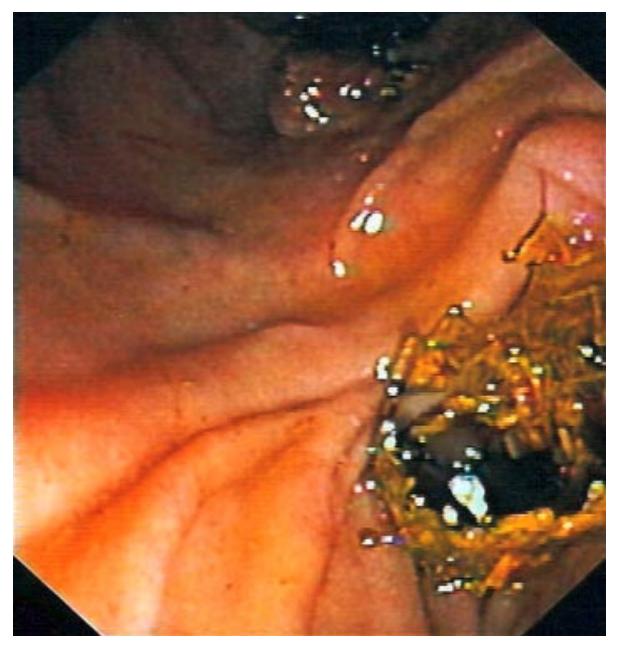


Fig. 3. Endoscopic view on the papilla with the correctly placed second metal stent.

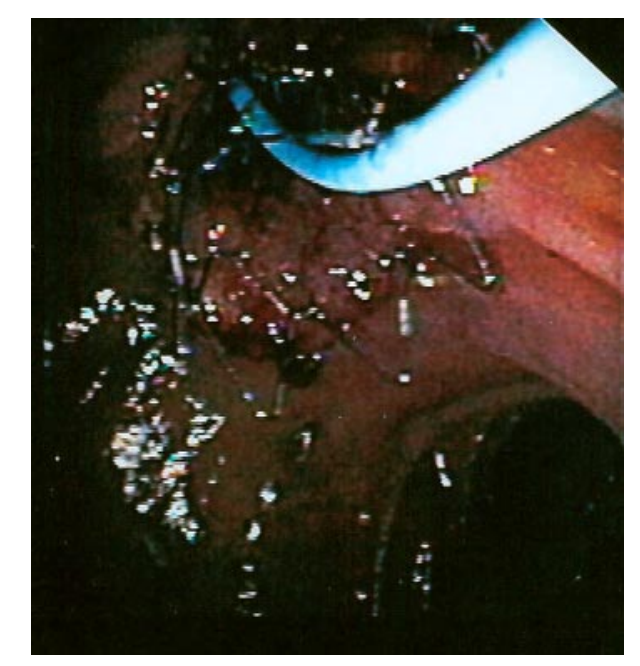




\section{References}

1 Srikureya W, Chang KJ: Endoscopic palliation of pancreatic adenocarcinoma. Curr Opin Gastroenterol 2005;21:601-605.

$\checkmark 2$ Brugge WR: Endoscopic techniques to diagnose and manage biliary tumours. J Clin Oncol 2005;23:4561-4565.

-3 Siriwardana HP, Siriwardana AK: Systematic appraisal of the role of metallic endobiliary stents in the treatment of benign bile duct structure. Ann Surg 2005;242:10-19.

-4 Eisendrath P, Deviere J: Expandable metal stents for benign pancreatic duct obstruction. Am J Gastroenterol 1999;9:547-554.

5 Kozarek RA: Endoscopic palliation of esophageal malignancy. Endoscopy 2005;35:S9-S13.

6 Von Rahden BH, Stein HJ: Staging and treatment of advanced esophageal cancer. Curr Opin Gastroenterol 2005;21:472-477.

-7 Sargeant IR, Loizou LA, Tulloch M, Thorpe S, Brown SG: Recanalization of tube overgrowth: a useful new indication for laser in palliation of malignant dysphagia. Gastrointest Endosc 1992;38:165-169.

8 McManus K, Khan I, McGuigan J: Self-expanding oesophageal stents: strategies for re-intervention. Endoscopy 2001;33:601-604.

\9 Isayama H, Komatsu Y, Tsujino T, Sasahira N, Hirano K, Toda N, Nakai Y, Yamamoto N, Tada M, Yoshida H, Shiratori Y, Kawabe T, Omata M: A prospective randomized study of 'covered' versus 'uncovered' diamond stents for the management of distal malignant biliary obstruction. Gut 2004;53:729-734.

10 Marano BJ, Bonanno CA: Metallic biliary endoprosthesis causing duodenal perforation and acute upper gastrointestinal bleeding. Gastrointest Endosc 1994;40:257-258.

11 Ee H, Laurence BH: Haemorrhage due to erosion of a metal biliary stent through the duodenal wall. Endoscopy 1992;24:431-432.

12 Shaver CP, Brady P, Pinkas H: You don't have to retrieve to relieve: How and when to trim a self-expanding metal biliary stent. Endoscopy 2004;36:833.

13 Vanbierbliet G, Piche T, Caroli-Bose FX, Dumas R, Peten EP, Huet PM, Tran A, Demarquay JF: Endoscopic argon plasma trimming of biliary and gastrointestinal metallic stents. Endoscopy 2005;37:434-438. 